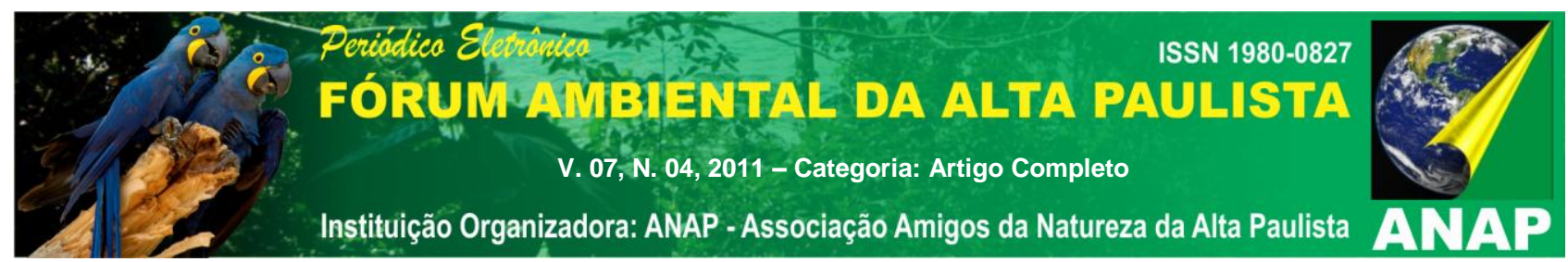

\title{
A AGENDA 21 E A ELABORAÇÃO DE POLÍTICAS PÚBLICAS PARA A SUSTENTABILIDADE URBANA
}

\author{
Geraldo Jose Ferraresi de Araujo ${ }^{1}$
}

\author{
Cesar Machado de Carvalho ${ }^{2}$
}

\begin{abstract}
Resumo: Com os sinais de esgotamento do atual modelo de produção, a sustentabilidade, modelo que contempla o desenvolvimento econômico e social, juntamente com a preservação ambiental, construído ao longo dos encontros internacionais promovidos pelas Nações Unidas (Estocolmo 72 e Rio 92) e pelo Relatório Bruntland e sintetizados num conjunto de premissas para as nações modificarem o vetor de desenvolvimento, chamado Agenda 21.Logo, as cidades, são espaços privilegiados para aplicação dos pressupostos das Agenda 21, juntamente, no caso brasileiros, com o Estatuto das Cidades para a transformação dos espaços urbanos, marcadas pela exclusão social e problemas estruturais. Sendo assim, o presente artigo tem como objetivo responder a seguinte pergunta: a Agenda 21 serve como referência para a elaboração de políticas públicas no Brasil?. Através do método qualitativo, foi realizado uma revisão bibliográfica dos principais autores relacionados a sustentabilidade urbana, onde pode-se responder positivamente a resposta. Porém, mesmo o Brasil, sendo signatário da Agenda 21 e o Estatuto das Cidades tendo força de lei, a aplicação destes dois instrumentos na elaboração e execução de políticas públicas e praticamente nula no Brasil diante dos problemas socioambientais nos grandes centros urbanos do país, evidenciando a falta de articulação e pró atividade dos poderes executivo, legislativo e judiciário nas três esferas. Faz-se necessário maior sinergia os três poderes em suas esferas para que os gestores públicos juntamente com a sociedade estejam comprometidos com a elaboração e execução de políticas públicas alinhadas com os princípios defendidos na Agenda 21 e em consonância com o Estatuto das Cidades.
\end{abstract}

Palavras Chave: Sustentabilidade Urbana. Políticas Públicas. Agenda 21.

1 IINTRODUÇÃO

\footnotetext{
${ }^{1}$ Bacharel em Administração pela Faculdade de Economia, Administração e Contabilidade de Ribeirão Preto da Universidade de São Paulo (Avenida dos Bandeirantes 3900, CEP14040-900 - Ribeirão Preto/SP, Brasil). E mail: geraldoferraresi@gmail.com. Fone: 55163602 - 3916. Fax: 5516 3633-4411.

${ }^{2}$ Mestrando em Ciências Políticas pela Universidade Federal de São Carlos, Campus São Carlos (Rodovia Washington Luís, Km 235, CEP: 13565-905 - São Carlos/SP, Brasil) Email:cesarmc27@yahoo.com.br. Fone: (16) 3351-8369.
} 


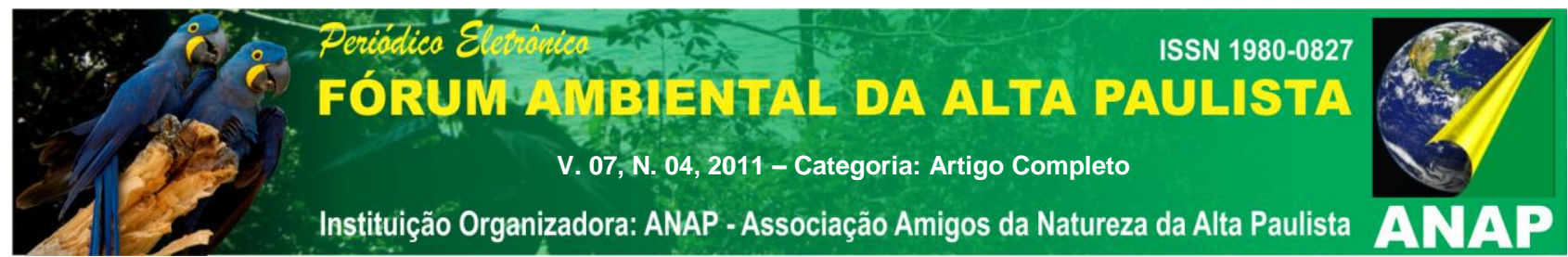

A sustentabilidade assumiu, no final do século $X X$, um papel chave na reflexão em torno do modelo de desenvolvimento econômico vigente e seus impactos sociais e ambientais tanto em escala regional quanto global.

O conceito de desenvolvimento sustentável, portanto, surgiu para enfrentar a crise ecológica que se apresentava, onde duas correntes de pensamento emergiram para elaboração e debate de novas propostas de desenvolvimento. (JACOBI, 1999)

Em 1972, Clube de Roma, composto por cientistas, empresários e políticos, publicou o seu relatório The Limits of Growth (Os limites do Crescimento), que alertava para o fato de que a humanidade teria, obrigatoriamente, um limite de crescimento com o modelo econômico então praticado, baseado no consumo e altamente concentrado em poucas nações, onde e era necessário o congelamento do crescimento da população global e do capital industrial, mostrando a limitação dos recursos naturais e indicando um viés malthusiano. (IBAMA, 2009)

Também em 1972, foi realizada Conferência das Nações Unidas para o Meio Ambiente Humano, a Conferência de Estocolmo, realizada em 1972 na Suécia, foi a primeira Conferência global voltada para o meio ambiente, e como tal é considerada um marco histórico político internacional, decisivo para o surgimento de políticas de gerenciamento ambiental, direcionando a atenção das nações para as questões ambientais. (PASSOS, 2009).

Nessa Conferência foram aprovados 25 princípios fundamentais que orientam as ações internacionais na área ambiental, tais como: a valorização do homem dentro do ambiente como ser que o transforma, mas que depende dele para sobreviver. Além disso, promove o progresso social, cria riquezas e desenvolve a ciência e a tecnologia. (IBAMA, 2009).

Em 1987, a Comissão de Meio Ambiente e Desenvolvimento da ONU elaborou o Relatório Bruntland, denominado Our Common Future, que contém informações colhidas pela comissão ao longo de três anos de pesquisa e análise, destacando-se as questões sociais, no que se refere ao uso da terra, sua ocupação, suprimento de água, serviços sociais, educativos e sanitários, além de administração do crescimento urbano.(BARBOSA, 2009). 


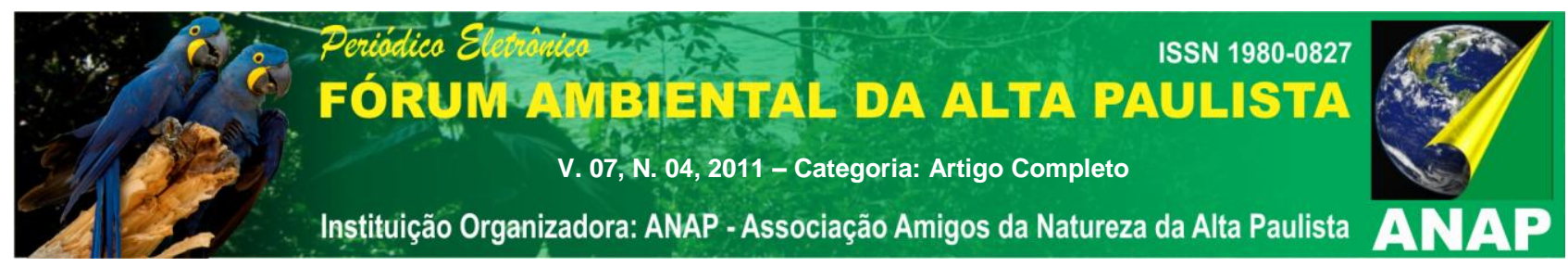

Segundo Barbosa (2008, p. 2) "O relatório ainda ressaltou, em relação às questões urbanas, a necessidade de descentralização das aplicações de recursos financeiros e humanos, e a necessidade do poder político favorecer as cidades em sua escala local."

Vinte anos depois da Conferência de Estocolmo, foi realizado no Rio de Janeiro a Conferencia das Nações Unidas para o Ambiente e Desenvolvimento, a Eco 92, que reuniu 108 chefes de estado para buscar mecanismos que rompessem com o abismo de desenvolvimento entre países ricos e pobres e ao mesmo tempo preservando o meio ambiente.

Através da Rio 92, foi introduzido o conceito de desenvolvimento sustentável, modelo que abarca crescimento econômico, preservação ambiental e inclusão social. Dentre os acordos internacionais decorridos do encontro foram: Convenção do Clima, Agenda 21, Convenção da Biodiversidade e a Declaração do Rio. Esses acordos deram margem a regulamentações, em relação a esses temas por parte das agências ambientais de vários países.

Especificamente no que se refere à agenda 21, segundo Silva, M. (2003, p.1) "reúne o conjunto de premissas e recomendações sobre como as nações devem agir para alterar seu vetor de desenvolvimento em favor de modelos sustentáveis e a iniciarem seus programas de sustentabilidade".

Dez anos depois, foi realizado em Joannesburgo, na África do Sul a Conferência das Nações Unidas sobre Ambiente e Desenvolvimento Sustentável, a Rio + 10, que reuniu cerca de cem chefes de Estado e mais de 15 mil representantes da sociedade civil. (FOLHA ON LINE, 2002)

A Declaração de Joannesburgo reafirmou os compromissos firmados na Eco 92, a Declaração elencou os desafios que foram e estão sendo enfrentados pelas nações participantes do encontro, reafirmou do compromisso com o desenvolvimento sustentável, a importância do multilateralismo democrático e responsável e assumiram o compromisso de agir em conjunto para a concretização dos objetivos propostos . (COMITE DE QUALIDADE DA GESTÃO PUBLICA, 2002)

Em linhas gerais, o desenvolvimento sustentável, de acordo com o Relatório Bruntland (1991, p.10) 


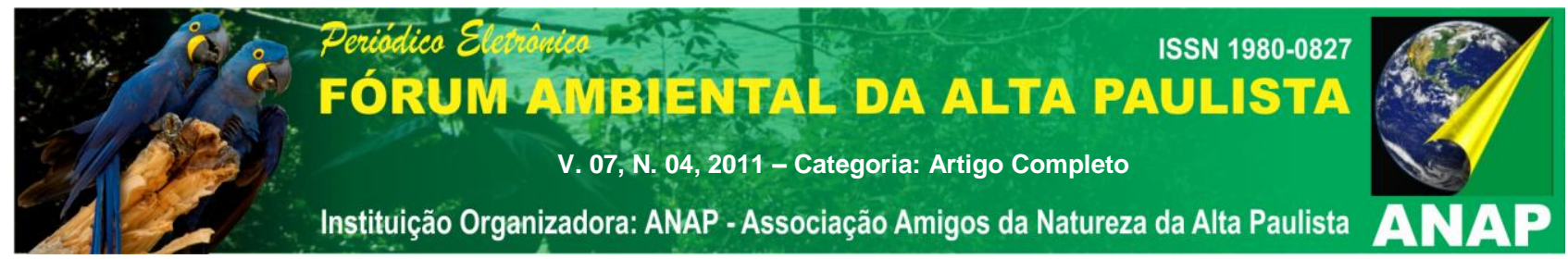

O desenvolvimento que procura satisfazer as necessidades da geração atual, sem comprometer a capacidade das gerações futuras de satisfazerem as suas próprias necessidades, significa possibilitar que as pessoas, agora e no futuro, atinjam um nível satisfatório de desenvolvimento social e econômico e de realização humana e cultural, fazendo, ao mesmo tempo, um uso razoável dos recursos da terra e preservando as espécies e os habitas naturais.

Para a execução dos compromissos assumidos pelos países nos fóruns internacionais promovidos pelas Nações Unidas (Estocolmo 72, Rio 92 e Joannesburgo 2002), faz se necessário, para Bursztyn (2001), que o estado atue como vetor de apoio ao desenvolvimento sustentável. Para isso, deve atuar através de instrumentos econômicos e legais. Além disso, os estados nacionais

[...] devem se concentrar na regulamentação, na gestão de contratos sociais, na promoção de instrumentos e políticas indutoras de estratégias planejadas, na garantia da proteção social [...]. O Estado tem enorme responsabilidade no desenvolvimento econômico e social de um país e sobre a sustentabilidade do desenvolvimento. (BIRD, 1997, p.157).

Bezerra e Bursztyn (2000) definem o desenvolvimento sustentável como um direcionador de políticas públicas orientadas por um plano de desenvolvimento nacional. Assim, a pluralidade de atores sociais e interesses presentes na sociedade colocam-se como um entrave para as políticas públicas para o desenvolvimento sustentável, ou seja, que contemplem concomitantemente o desenvolvimento econômico, social e a preservação ambiental.

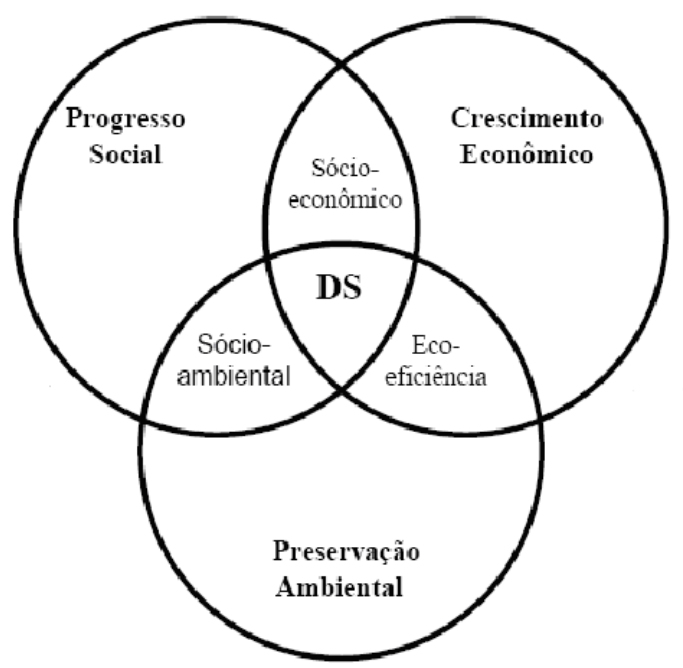




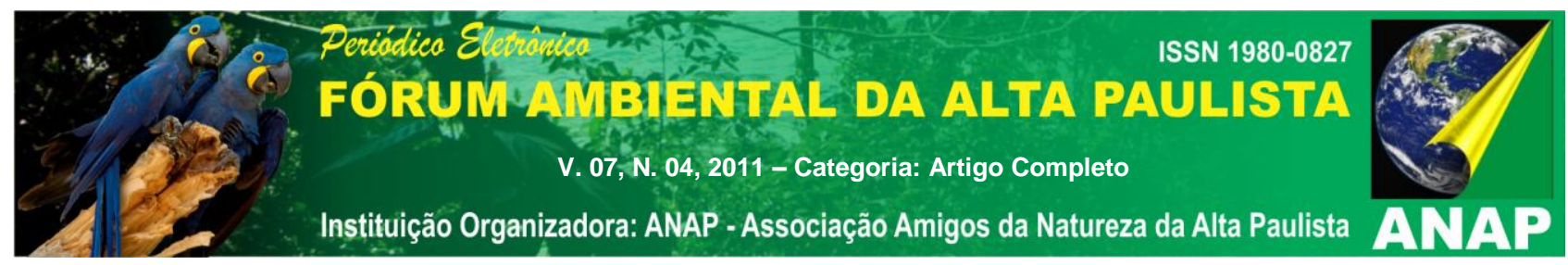

Figura 1: As três dimensões do desenvolvimento sustentável. Fonte: Kraemer (2003, apud ARAUJO, 2006, p. 83).

Para Bucci (2002, p.24), políticas públicas "são programas de ação governamental visando a coordenar os meios à disposição do Estado e as atividades privadas, para a realização de objetivos socialmente relevantes e politicamente determinados". Além disso, para Muller (1998, p. 16), políticas públicas são "programa de ação governamental para um setor da sociedade ou um espaço geográfico".

As cidades, sendo um espaço geográfico, são fundamentais para a edificação de políticas publicas que contemplem 0 tripé social, ambiental e econômico da sustentabilidade.

Logo, para Silva, T. (2003) a sustentabilidade urbana implica em repensar o modelo de desenvolvimento, as relações sociais, ambientais e econômicas nas cidades. Trata-se, portanto, manter a saúde de seu sistema ambiental, reduzir a desigualdade social, prover seus habitantes de um ambiente construído saudável, bem como construir pactos políticos e ações de cidadania que o permitam enfrentar desafios presentes e futuros. (Acserald,1999)

\section{$1.1 \quad$ OBJETIVO DE ESTUDO}

O presente artigo tem como objetivo discorrer sobre a evolução do debate sobre o desenvolvimento sustentável e como este, através dos princípios defendidos pela Agenda 21, pode servir como norte, juntamente com o Estatuto das Cidades, para a elaboração de políticas públicas que contemplem a sustentabilidade urbana.

Onde a pergunta que se pretende responder neste trabalho é: a Agenda 21 serve como referência para a elaboração de políticas públicas no Brasil?

\subsection{METODOLOGIA}

A natureza do método empregado neste estudo é do tipo qualitativo. Para Liebscher (1998) são apropriados quando o fenômeno em estudo é complexo, de 


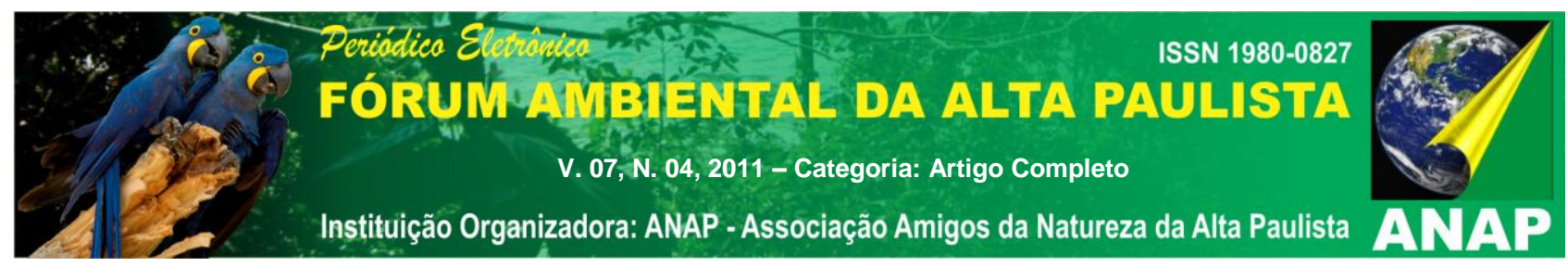

natureza social e não tende à quantificação. Normalmente, são usados quando o entendimento do contexto social e cultural é um elemento importante para a pesquisa.

Para alcançar o objetivo da pesquisa, foram realizados levantamento bibliográfico nas bases dados do Instituto Brasileiro do Meio Ambiente e dos Recursos Naturais Renováveis, o IBAMA; Ministério das Cidades; Programa das Nações Unidas Para o Meio Ambiente e Folha de São Paulo. Além dos principais autores relacionados a temática da sustentabilidade urbana, como Pedro Jacobi.

Os mesmos foram acessadas através da INTERNET, no período de março a agosto de 2011. Nessas bases de dados foram cruzadas as seguintes palavras-chaves: cidades, políticas públicas, desenvolvimento sustentável e sustentabilidade urbana, posteriormente, foram avaliados os artigos de maior relevância no assunto, através da consulta as referencias bibliográfica, sob o resumo dos artigos.

\section{A SITUAÇÃO DAS CIDADES SOCIO AMBIENTAL DAS CIDADES BRASILEIRAS CONTEMPORANEAS}

Para Romualdo e Souza (2009) o acelerado processo de urbanização das cidades brasileiras, ocorrido a partir da década de 1960, associado à falta de planejamento originou uma série de problemas ambientais, sociais e econômicos: aumento de ocorrência de enchentes; crescente despejo inadequado de resíduos sólidos; ocupações irregulares de áreas ambientalmente frágeis, como encostas e áreas alagáveis; assentamentos ilegais, marcados pela exclusão social e pelo acesso diferenciado aos investimentos públicos; problemas de saneamento ambiental decorrentes do baixo índice de coleta e tratamento de esgotos; poluição do ar e aumento do volume de resíduos sólidos (Costa e Braga, 2004).

No geral, para Jacobi (2006), observa-se um crescente agravamento dos problemas ambientais nos grandes centros urbanos brasileiros, já que o modelo de apropriação do espaço reflete as desigualdades socioeconômicas, sendo marcado pela ineficácia de políticas públicas para o enfrentamento dos problemas elencados acima, predominando a inércia da administração pública na detecção, correção e proposição de 


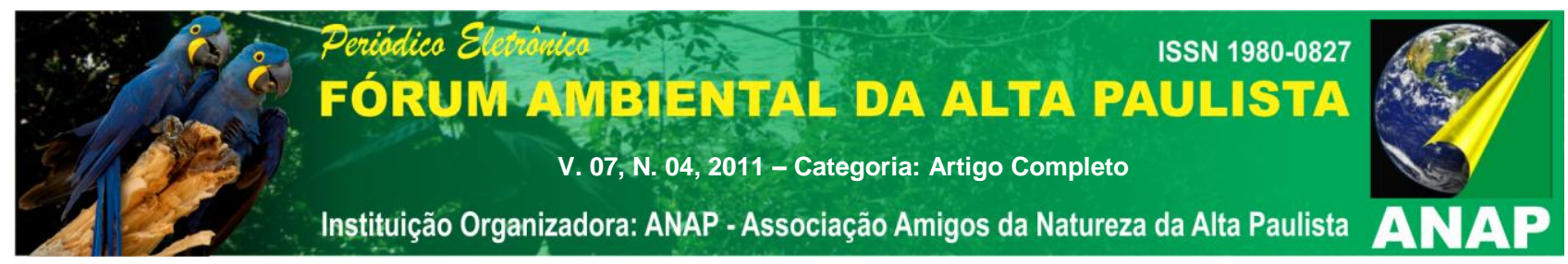

medidas visando ordenar o espaço urbano e garantir a melhoria da qualidade de vida para todos seus cidadãos.

A crise ambiental, como resultado de práticas administrativas inadequadas por parte das autoridades municipais, bem como a omissão e a demora da aplicação de políticas públicas que reduziriam os problemas crescentes e prejudiciais, está vinculada, para Jacobi (2006), às seguintes questões:

- Redução de áreas verdes, o que implica na impermeabilização do solo e na multiplicação de áreas de ocorrência de enchentes, com impactos ambientais, sociais e econômicos sobre toda a cidade;

- Ausência de políticas públicas para controle da poluição do ar, ampliação do sistema de transporte coletivo e expansão da rede de esgoto;

- Contaminação dos mananciais de água e dos rios nas cidades e o risco para a população;

- Exaustão dos métodos convencionais de despejo de lixo e os problemas resultantes da contaminação das águas subterrâneas e de superfície pelo chorume;

- Precariedade das condições de moradia de uma parcela da população, geralmente localização em áreas de risco.

Segundo Bentes (2006), o planejamento urbano no Brasil, nas décadas de 1980 e 1990, foi relegado ao segundo plano, principalmente, como forma de negação ao planejamento praticado pelos governos militares, de forma autoritária, burocrática e centralizadora gerou graves problemas urbanos.

Para Guerra e Cunha (2006, p.39), “quando o crescimento urbano não é acompanhado por aumento e distribuição eqüitativa dos investimentos em infra-estrutura e democratização do acesso aos serviços urbanos, às desigualdades socioespaciais são geradas ou acentuadas". Jacobi (2006) ratifica que nestas circunstâncias, as cidades, assim como suas respectivas regiões metropolitanas, se caracterizam por enormes desigualdades na distribuição de renda.

Logo, o avanço da pobreza e consequentemente a violência tem suas origens e sua reprodução em uma superposição de carências. A diminuição da pobreza, entretanto, 


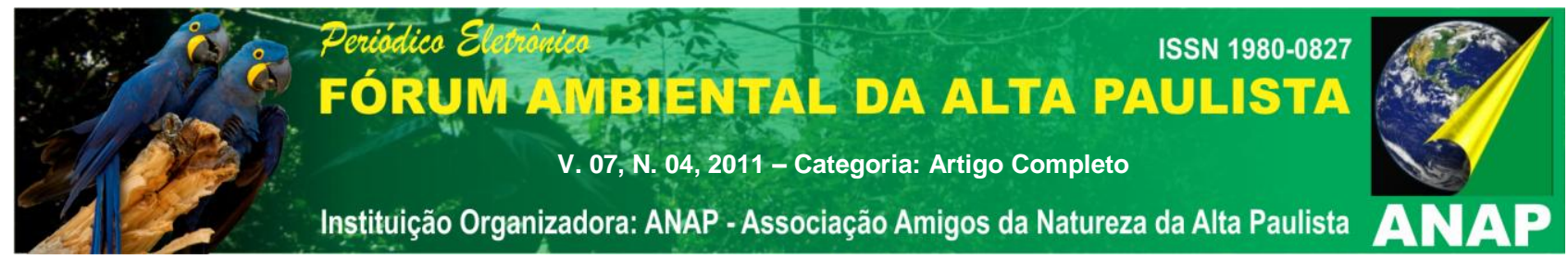

passa muito mais pela capacidade do poder público em responder adequadamente a essas carências através de políticas públicas coordenadas.

No atual quadro urbano brasileiro, é inquestionável a necessidade de implementar políticas públicas intersetorialidade em âmbito municipal e regional onde a dimensão socioambiental estimula uma perspectiva de sustentabilidade, assim reforçando a sua articulação com políticas de emprego, renda e desenvolvimento econômico sustentáveis como forma de se contrapor ao quadro de deterioração crescente das condições de vida. (Jacobi, 2006).

\section{AS POLITICAS PÚBLICAS E O ESTATUTO DAS CIDADES}

Diante da realidade dos centros urbanos brasileiros, conforme discorrido no capítulo 2, tornar as cidades sustentáveis, segundo Jacobi (1999) é desafio que está colocado em relação à formulação e propostas de políticas públicas que contribuam para alcançar objetivos de sustentabilidade nas cidades.

Para Silva, T. (2003) a adoção de políticas públicas buscando a sustentabilidade urbana implica em repensar o modelo de desenvolvimento, uma necessária inter-relação entre justiça social, qualidade de vida, equilíbrio ambiental e o desenvolvimento. Isto representa a possibilidade de garantir mudanças sociopolíticas que não comprometam os sistemas ecológicos e sociais nos quais se sustentam as comunidades. (Jacobi, 2006)

As políticas municipais têm o desafio de incorporar a sustentabilidade enquanto diretriz norteadora, pautando-se pelas premissas que definem a Agenda 21, onde o tema sustentabilidade implica numa necessária inter-relação entre eqüidade social, qualidade de vida, desenvolvimento com capacidade de suporte e participação. (Jacobi, 2006)

Para tanto, cabe ao poder legislativo, a responsabilidade de elaborar as políticas públicas, poder executivo sua realização e ao poder judiciário, em caso de omissões do Poder Público na execução das políticas públicas que contemplem no espaço urbano o desenvolvimento sustentável, determinar por meio de ações judiciais, que o executivo cumpra tais medidas.

Porém a Lei n. 10.257, de 10 de julho de 2001, conhecida como o Estatuto das Cidades, especificamente em seu inciso I do art. $2^{\circ}$, garante aos cidadãos "o direito a 


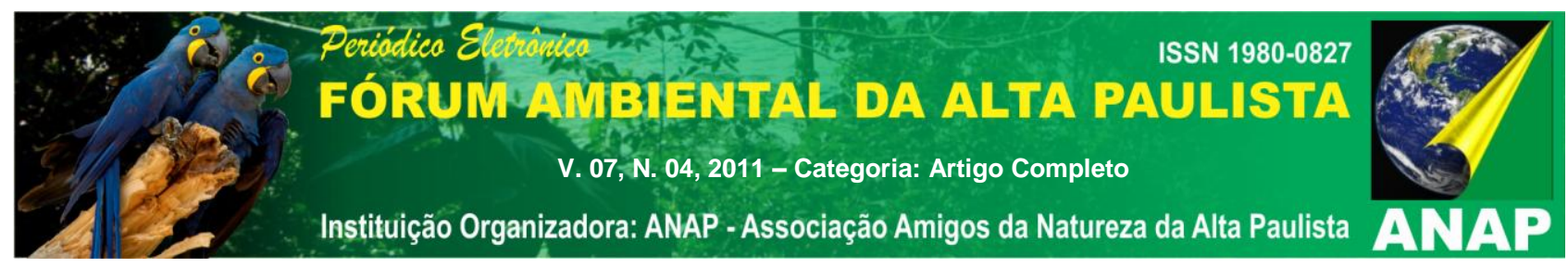

cidades sustentáveis, entendido como o direito à terra urbana, à moradia, ao saneamento ambiental, à infra-estrutura urbana, ao transporte e aos serviços públicos, ao trabalho e ao lazer, para as presentes e futuras gerações" e paralelamente, obriga os municípios a executarem políticas públicas que contemplem o direito a cidades sustentáveis pelos cidadãos.

Para Silva, T. (2003, p.8) o Estatuto das Cidades representa

consagração entre as diretrizes gerais da política urbana a garantia do direito a cidades sustentáveis. Esse direito é entendido como o direito à terra, à moradia, ao saneamento ambiental, à infra-estrutura urbana, ao transporte e aos serviços públicos, ao trabalho e ao lazer, para as presentes e futuras gerações. O desenvolvimento das cidades deverá, portanto, respeitar os limites da sustentabilidade, ou seja, o desenvolvimento urbano deve ocorrer com "ordenação, sem caos e destruição, sem degradação, possibilitando uma vida urbana digna para todos". Trata-se de um direito coletivo da população a cidades sustentáveis, ou seja, o direito ao acesso a condições de vida urbana digna, ao meio ambiente ecologicamente equilibrado e aos equipamentos e serviços públicos.

\section{$4 \quad$ O ESTATUTO DAS CIDADES E A AGENDA 21}

A "Agenda 21", documento aprovado na Rio 92, é um plano de ação para ser adotado global, nacional e localmente, onde estabeleceu diretrizes para mudança do padrão de desenvolvimento no século XXI. Trata-se da tentativa de promover, no mundo todo, um novo padrão de desenvolvimento que venha a conciliar os instrumentos de proteção ambiental, eqüidade social e desenvolvimento econômico.

O termo "Agenda" foi concebido no sentido de intenções de mudanças para um modelo de desenvolvimento em que predominasse o equilíbrio ambiental e a justiça social entre as nações.

Para Silva, M. (2003, p. 1)

Agenda 21 é um processo de planejamento participativo que resulta na análise da situação atual de um país, estado, município, região, setor e planeja o futuro de forma sustentável. E esse processo deve envolver toda a sociedade na discussão dos principais problemas e na formação de parcerias e compromissos para a sua solução a curto, médio e longo prazos. A análise do cenário atual e o encaminhamento das propostas para o futuro devem ser realizados dentro de uma abordagem integrada e sistêmica das dimensões econômica, social, ambiental e político-institucional da localidade. Em outras palavras, o esforço de planejar o futuro, com base nos princípios da Agenda 21, gera inserção social e 


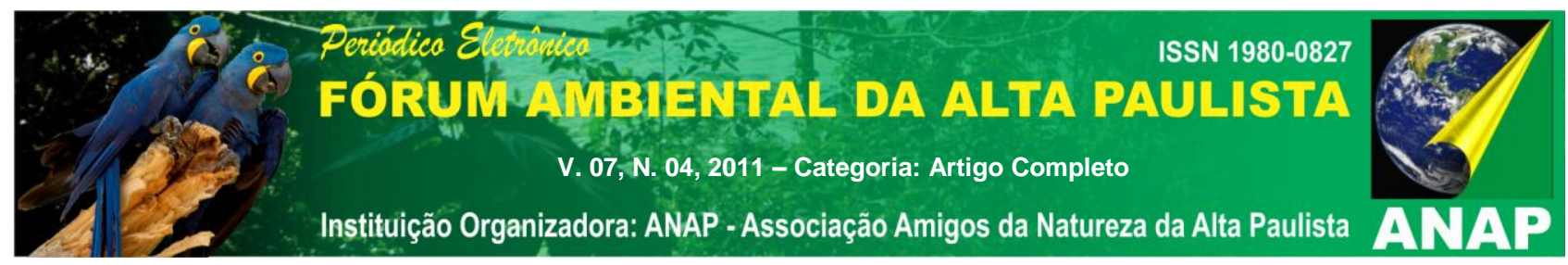

oportunidades para que as sociedades e os governos possam definir prioridades nas políticas públicas.

Especificamente no capítulo 28 da Agenda 21 estabelece, segundo Silva, M. (2003, p.3) cada país realize uma Agenda 21 local "tendo como base de ação o desenvolvimento econômica e social e a preservação ambiental local, estabelecendo políticas ambientais locais e prestando assistência na implementação de políticas ambientais nacionais."

Neste contexto, o Estatuto das Cidades entra em consonância com os princípios da Agenda 21, na medida em que ambos defendem em nível local, mudanças nos modos operantes do desenvolvimento através de implementação de agendas locais, pois reconhece a importância do nível local na concretização de políticas públicas sustentáveis.

Para Silva, T. (2003) para que as cidades brasileiras do século XXI possam vir a se adequar as propostas da Agenda 21 e ao Estatuto da Cidade, será necessário transformações dos padrões insustentáveis de produção e consumo que resultam na degradação dos recursos naturais e econômicos, afetando a qualidade de vida da população nas cidades.

Entre as propostas estratégicas de sustentabilidade urbana, identificadas como prioritárias para o desenvolvimento sustentável das cidades brasileiras, encontram-se as seguintes:

- Regulamentação do uso e da ocupação do solo urbano, contribuindo para a melhoria da qualidade de vida da população;

- Fortalecimento da gestão democrática das cidades, incorporando no processo a dimensão ambiental urbana e assegurando a participação de todos os cidadãos nos processos decisórios como um meio de fortalecer a sua co-responsabilização no monitoramento dos agentes responsáveis pela degradação socioambiental;

- Mudança no modelo de produção e de consumo da cidade, reduzindo desperdícios e fomentando a elaboração e implementação de políticas públicas urbanas sustentáveis;

- Geração de empregos através de políticas públicas de caráter sustentável;

- Desenvolvimento e a aplicação de mecanismos econômicos na administração dos recursos naturais visando à sustentabilidade urbana; 


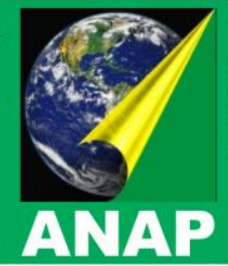

- Planejamento e uso do solo e o acesso aos serviços de saneamento básico

- Sistemas de limpeza urbana - redução do lixo, reciclagem e coleta seletiva, políticas de destinação de resíduos;

- Ampliar o nível de consciência ambiental dos cidadãos através da aducação ambiental;

- Fomento ao desenvolvimento de tecnologias urbanas sustentáveis, como em matéria de construção civil.

A sociedade brasileira, hoje, majoritariamente urbana, as dimensões sociais e ambientais têm e terão cada vez mais um papel predominante na determinação das políticas públicas nas cidades. Logo, se trata de conquistar condições dignas de vida urbana a todos, buscando um equilíbrio social, econômico e ambiental do planeta.

Portanto, a necessidade de democratização nas escolhas prioritárias de cada sociedade, essas escolhas fundamentarão as ações e os programas governamentais, ou seja, as políticas públicas (Silva,T. 2003).

No Brasil, a os princípios norteadores da agenda 21, juntamente com o Estatuto das Cidades e as extensas pesquisas sobre os grandes problemas urbanos brasileiros, são de fundamental importância para os três poderes (Executivo, Legislativo e Judiciário) para elaboração, execução e fiscalização de políticas públicas sustentáveis, que contemplem os espaços urbanos e que vão ao encontro do equilíbrio econômico, social e ambiental.

\section{CONCLUSÃO}

O presente artigo procurou responder a seguinte questão: a Agenda 21 serve como referência para a elaboração de políticas públicas no Brasil?

Através da revisão bibliográfica utilizada pode-se responder afirmativamente a essa questão, pois na medida em que se observa o esgotamento do atual modelo de produção e desenvolvimento através dos impactos socioambientais tanto em escala global: efeito estufa; destruição da camada de ozônio; devastação de florestas nativas; desertificação e bolsões de pobreza no continente africano, América latina e sudeste asiático; quanto regionais: violência, construções e áreas de risco, sistemas de transporte inadequados, 


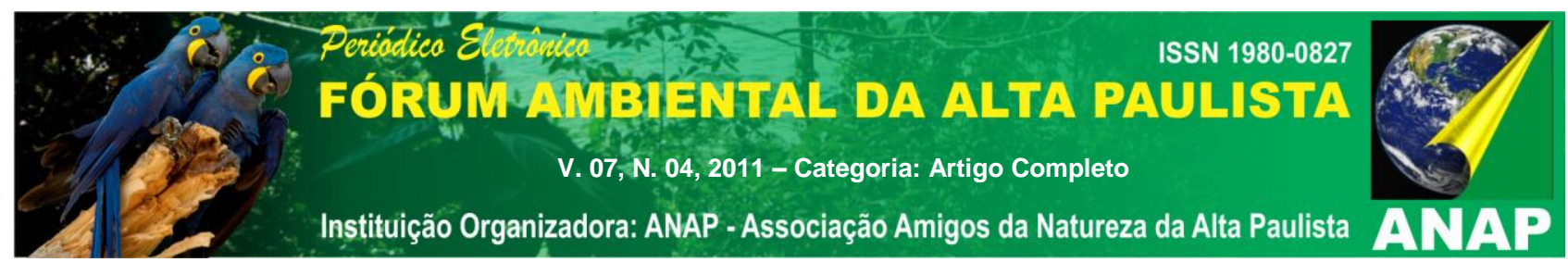

precariedade no sistema de esgoto, sistemas de educação e saúde de baixa qualidade, chuvas acidas, enchentes, inversões térmicas e ilhas de calor.

Logo, os princípios defendidos pela Agenda 21 representam uma alternativa, que responde tanto as necessidades econômicas e sociais quanto as inerentes limitações do meio ambiente.

Porém sendo a definição de políticas públicas programas de ação governamental visando a coordenar os meios à disposição do Estado e as atividades privadas, para a realização de objetivos socialmente relevantes e politicamente determinados, pode-se observar que na maioria das cidades brasileiros, como pode se verificar no capitulo 2 deste artigo através dos referenciais teóricos utilizados, que as políticas públicas de âmbito local não tem como norte tanto a Agenda 21, quanto o Estatuto das Cidades.

Esta situação se da em linhas gerais devido: a falta de articulação política tanto na esfera ministerial, quanto do governo federal para com os estados e municípios, falta de visão sistêmica por parte dos gestores públicos no que se refere aos principais problemas urbanos brasileiros e a omissão por parte do poder judiciário que tange em fazer cumprir o Estatuto da Cidade, na medida em que o referido estatuto possui força de lei.

Portanto, para que o Brasil se adeque as inevitáveis transformações do século XXI, referentes aos agravamentos dos cenários econômicos, sociais e ambientais em escala global, é necessária a articulação política nas três esferas de poder, gestores públicos comprometidos com a elaboração e execução de políticas públicas alinhadas com os princípios defendidos na Agenda 21 e em consonância com o Estatuto das Cidades, para que as cidades brasileiras e o próprio país estejam preparados para a mudança de paradigma de desenvolvimento, a sustentabilidade.

\section{REFERÊNCIA}

ACSELRAD, Henry. Discursos da sustentabilidade urbana. Revista Brasileira de Estudos Urbanos e Regionais, Campinas, n.1, p.79-90, maio 1999.

BARBOSA, Gisele Silva. O desafio do desenvolvimento sustentável. Revista Visões, Macaé, V. 1, № 4, p. 1-11, 2008. Disponível em:

<http://www.fsma.edu.br/visoes/ed04/4ed_O_Desafio_Do_Desenvolvimento_Sustentavel_ Gisele.pdf> Acesso em: 10 Ago. 2011. 


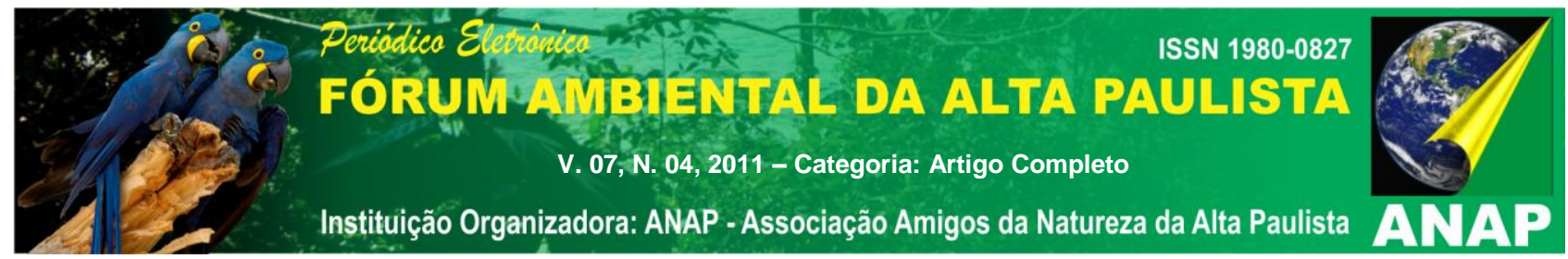

BENTES, Julio Claudio da Gama. Desenvolvimento Sustentável Urbano - Conceitos e Instrumentos de Gestão para Cidades Sustentáveis. Rio de Janeiro: COPPE - UFRJ, 2006.

BEZERRA, Maria do Carmo Lira; BURSZTYN, Marcel. (cood.). Ciência e Tecnologia para o desenvolvimento sustentável. Brasília: Ministério do Meio Ambiente e dos Recursos Naturais Renováveis: Consórcio CDS/ UNB/ Abipti, 2000.

BIRD. World development Report 1997. The state in a changing world. The World Bank/Oxford University Press, Washington, 1997.

BRASIL. Lei n. 10.257, de 10 de julho de 2001. Institui normas regras para o desporto e da outras providências. Diário Oficial da União, Brasília, DF, 11 Jul. 2001.

BRUNDTLAND, Gro Harlem. Nosso futuro comum: comissão mundial sobre meio ambiente e desenvolvimento. 2.ed. Rio de Janeiro: Fundação Getúlio Vargas, 1991.

BUCCI, Maria Paula Dallari. Direito administrativo e políticas públicas. São Paulo: Saraiva, 2002. p. 241.

BURSZTYN, Marcel. Políticas públicas para o desenvolvimento sustentável. In: A difícil sustentabilidade. Política energética e conflitos ambientais. Ed. Garamond, Rio de Janeiro, 2001.

COMITE DE QUALIDADE DA GESTÃO PUBLICA. Declaração de Johanesburgo sobre Desenvolvimento Sustentável. 2002. Disponível em: <

http://www.cqgp.sp.gov.br/gt_licitacoes/publicacoes/joanesburgo.pdf> Acesso em: 10 Jul. 2011.

COSTA, Heloisa; BRAGA, Tânia. Entre a conciliação e o conflito: dilemas para o planejamento e a gestão urbana e ambiental. In: ACSELRAD, Henri (org.). Conflitos Ambientais no Brasil. Rio de Janeiro: Relume Dumará, 2004. p. 195-216.

FOLHA ON LINE. Saiba o que é a Rio + 10. 2002. Disponível em:

<http://www1.folha.uol.com.br/folha/especial/2002/riomais10/o_que_e.shtml> Acesso em: 10 Jul. 2011. 


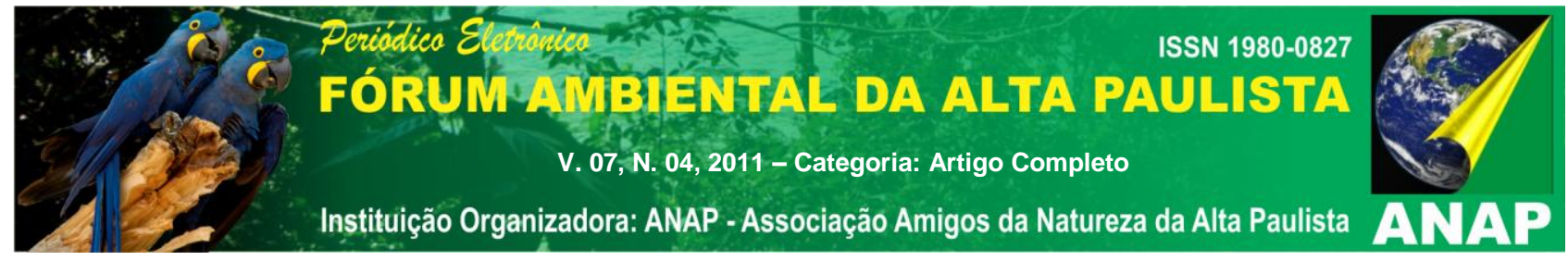

GUERRA, Antonio Jose Teixeira; CUNHA, Sandra Babtista. Impactos Ambientais Urbanos no Brasil. 4ª ed. Rio de Janeiro: Bertrand Brasil, 2006.

Instituto Brasileiro do Meio Ambiente e dos Recursos Naturais Renováveis. História. Disponível em: <http://www.ibama.gov.br/am/institucional/historia.htm>. Acesso em: 10 Ago. 2011.

JACOBI, Pedro. Dilemas Socioambientais na gestão metropolitana: Do risco a busca da sustentabilidade urbana. Política e Trabalho, João Pessoa, № 25, p. 115-134 Out. 2006.

KRAEMER, M. E. P. Contabilidade rumo á pós-modernidade: um futuro sustentável, responsável e transparente, 2005. In ARAUJO, G. C. O Processo de implantação da sustentabilidade em frigoríficos: Estudo de caso no Frigorífico Independência. 2006. 169 f. Dissertação (Mestrado em Agronegócio) - Universidade Federal do Mato Grosso do Sul, Campo Grande, 2006.

LIEBSCHER, Peter. Quantity with quality ? Teaching quantitative and qualitative methods in a LIS Master's program. Library Trends, v. 46, n. 4,p. 668-680, Spring 1998.

MULLER, Pierre; SUREL, Yves. L'Analyse des Politiques Publiques. Paris: Montchrestien, 1998. p. 156.

PASSOS, Priscilla Nogueira Calmon, A Conferência de Estocolmo como ponto de partida para a proteção internacional do meio ambiente. Revista Direitos Fundamentais e Democracia, Curitiba, V. 6, N 6, p. 1-25, 2009. Disponível em: < http://revistaeletronicardfd.unibrasil.com.br/index.php/rdfd/article/viewFile/266/195> Acesso em: 10 Jul. 2011.

SILVA, Solange Teles. Políticas públicas e estratégias de sustentabilidade urbana. Hiléia. Manaus, v. 1, n. 1, p. 121-137, 2003. Disponível em: < http://www3.esmpu.gov.br/linhaeditorial/outras-publicacoes/serie-grandes-eventos-meioambiente/Solange_Teles_Politicas_publicas_e_sustentabilidade.pdf >. Acesso em: $10 \mathrm{Jul}$. 2011.

SILVA, Marina. Agenda 21. Ministério do Meio Ambiente. Disponível em: $<$ http://www.mma.gov.br/sitio/index.php?ido=conteudo.monta\&idEstrutura=18\&idConteudo =597>. Acesso em: 10 Jul. 2011 . 


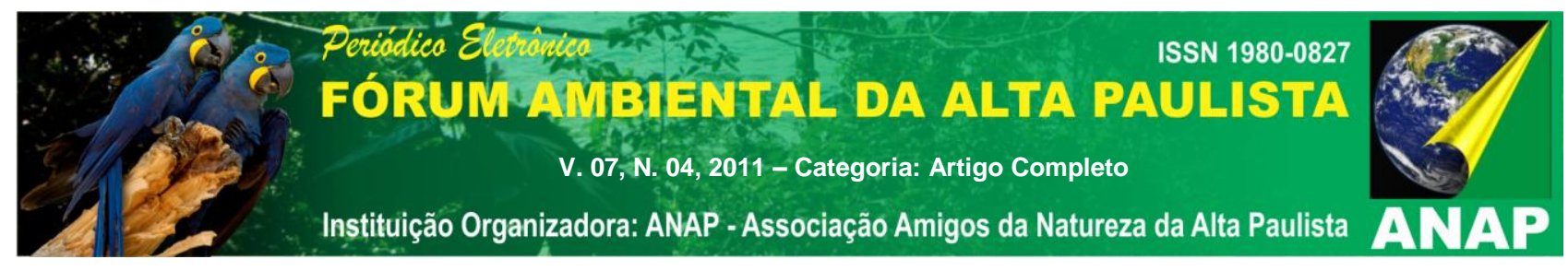

SOUZA, Graziella Martinez; ROMUALDO, Sanderson dos Santos. Inundações urbanas: A percepção sobre a problemática sócio ambiental pela comunidade do bairro Jardim Natal - Juiz de Fora (MG). In: SIMPÓSIO BRASILEIRO DE GEOGRAFIA FÍSICA E APLICADA DA UFV. 2009. Anais eletrônicos...Viçosa:UFV, 2009. Disponível em: < http://www.geo.ufv.br/simposio/simposio/trabalhos/trabalhos_completos/eixo11/038.pdf>. Acesso em: 10 Jul. 2011. 